\title{
Prenatal Exposure to Bisphenols and Parabens and Impacts on Human Physiology
}

\author{
L. KOLATOROVA ${ }^{1}$, M. DUSKOVA ${ }^{1}$, J. VITKU $^{1}{ }^{1}$ L. STARKA $^{1}$ \\ ${ }^{1}$ Department of Steroids and Proteofactors, Institute of Endocrinology, Prague, Czech Republic
}

Received May 9, 2017

Accepted May 29, 2017

\begin{abstract}
Summary
In modern societies, living organisms are exposed daily to multiform pollution from industrial chemical products. Some of these substances have been shown to affect the endocrine system, and have been termed endocrine disruptors (EDs). Bisphenol A (BPA), which can leach from plastics, and parabens, used in cosmetic products, are among the most well-studied. Prenatal development is a vulnerable phase of human life, and disruptions during this period may have lifelong consequences. Since EDs are known to cross the placental barrier and BPA may accumulate in the fetus, "BPA-free" products have been introduced to the market. However, such products often contain alternative bisphenols (e.g. BPS, BPF) that have not yet been extensively examined or regulated. Moreover, alternative bisphenols often occur together with BPA. The human organism is thus exposed to a mixture of EDs, some of which can have additive or synergic effects. Recent findings have also shown that paraben exposure can alter bisphenol pharmacokinetics. Taking into account the widespread occurrence of various EDs and the potential multiplicity of their effects, doses of EDs currently considered safe may not actually be as safe as they appear, especially during pregnancy.
\end{abstract}

\section{Key words}

Endocrine disruptor • Bisphenol • Paraben • Fetus • Pregnancy

\section{Corresponding author}

L. Kolatorova-Sosvorova, Department of Steroids and Proteofactors, Institute of Endocrinology, Narodni 8, 11694 Prague, Czech Republic. E-mail: Ikolatorova@endo.cz

\section{Introduction}

The development and progress of industry has been closely linked to widespread pollution and the occurrence of various chemicals in the environment as well as the food chain. Recent findings have shown that many chemicals have the ability to interfere with the endocrine system, and these substances have been termed endocrine disruptors (EDs). There is growing evidence of their negative impacts on living organisms (Bergman et al. 2013, Diamanti-Kandarakis et al. 2009), which are exposed to EDs mainly by the intake of contaminated food and fluids, breathing contaminated air or transdermally (Darbre 2015). EDs may alter the hormonal and homeostatic system and thus affect the metabolism, sexual development, growth, stress response, insulin production, gender behavior, reproduction and even fetal development of the living body (Kabir et al. 2015). Due to their ability to accumulate in organisms, they may also even affect the development of subsequent generations.

The term endocrine disruptor was initially defined at the turn of the millennium as any substance affecting the endocrine system. A more precise definition according to the Environmental Protection Agency defines an ED as an exogenous substance interfering with the synthesis, secretion, transport, binding, action or elimination of natural hormones responsible for the maintenance of homeostasis, reproduction, development and/or behavior. This term currently includes thousands of substances, and their number is still increasing. The issues surrounding EDs and their potential adverse effects on the human body are currently one of the more important scientific topics, and have also been discussed 
by the European Commission and European Parliament. In the European Union (EU), the main regulating organ concerning the usage of ED chemicals is the European Chemical Agency. The number of scientific reports dealing with EDs have increased rapidly, with many focusing on the relation of EDs to reproduction, thyroid gland functions, oncogenic action, relation to the onset and progress of puberty, and recently also to obesity.

The first EDs identified were those with estrogen-like activity, and even today the majority of these compounds are estrogen mimicking (i.e. xenoestrogens). They act additively with endogenous estrogens, although they usually have lower affinity towards classical nuclear estrogen receptors (ERs), and some, especially phytoestrogens, differ from natural hormonal estrogens in their specific affinities to ER- $\alpha$ and ER- $\beta$. Xenoestrogens are also bound to plasma carrier proteins with significantly lower affinities than natural estrogens and thus are more readily available to target cells. The same xenoestrogens that appear to be weak agonists for nuclear ERs may be strong agonists when acting through membrane ERs; this may explain their ability to produce biological effects at low doses (Gore 2007).

In the environment, many chemicals occur in parallel and the organism is usually exposed to a mixture of chemicals that may have additive or even synergic effects. Many EDs are persistent, resulting in their bioaccumulation in the food chain and the human body. The age when an organism is exposed to an ED can also be crucial. In adults, higher levels are usually needed to produce harmful effects, but during human development even very low doses can have lasting effects (Barker 2003). The aim of this review is to summarize recent knowledge concerning the effects of bisphenols and parabens on the development of the fetus.

\section{Effects on the fetus}

Recently, much attention has focused on fetal and neonatal exposure to EDs. The prenatal phase of human development is among the most active periods of life, and chemical signalization, based mainly on hormones, plays a significant role in fetal development. Although the sex of the fetus is determined genetically, gonadal hormones are further responsible for the differentiation of the male and female phenotypes. EDs mimicking or blocking natural sexual hormones may therefore interfere with natural development (Shekhar et al. 2017). Several phenotype variations and birth abnormalities have been connected with the influence of EDs, e.g. testicular dysgenesis syndrome (Skakkebaek et al. 2001) and low birth weight (Chang et al. 2013). Recurrent miscarriages (Sugiura-Ogasawara et al. 2005) have also been reported in relation to the occurrence of EDs.

Although the developing fetus is the most vulnerable to endocrine disruption, the effects of EDs may be expressed in other phases of the life cycle. EDs themselves exert epigenetic effects that may be passed to subsequent generations. If expressed in the germ line, this could create a vicious cycle in which an organism's epigenome may predispose it to a vulnerability to endocrine disruption. This in turn may lead to additional epigenetic modifications that are passed on to the offspring. In addition, the lifelong exposure to EDs, from embryonic development through old age, needs to be taken into account when considering the cumulative effects of EDs across the life cycle (Gore 2007).

\section{The fetal compartment}

The transport of exogenous substances across the placenta from the mother to the fetus is an important issue, with possible detrimental effects on the fetus in utero as well as later in life (Diamanti-Kandarakis et al. 2009, Schug et al. 2011). However, placentas of different species exhibit a large degree of specificity, due to anatomical and functional differences. This makes it difficult to interpret animal data with respect to fetal exposure during human pregnancy (Beck 1976). Overall, the human placenta seems to have higher impermeability to lipophilic substances compared to most experimental animals (Barry and Anthony 2008).

Mothers may be exposed to EDs at low levels during their lives, but because of their lipophilic properties EDs may accumulate in their fat stores. Pregnancy and breast feeding are energetically very expensive, and therefore these fat stores may be mobilized. This can result in the release of high concentrations of accumulated EDs, which may affect the underdeveloped reproductive and immune systems of the fetus and newborn child. The fetus may be constantly exposed to these chemicals, as they are excreted through the fetal urine into the amniotic fluid which surrounds the fetus (Modena and Fieni 2004). In addition, the fetal pharmacokinetics of various drugs and chemicals may be different than in adulthood. In particular, the fetus and 
neonate show a very limited first-pass metabolic capability for EDs (Matsumoto et al. 2002). Therefore, doses of EDs considered to be safe should not be assumed to be safe during pregnancy (Matsumoto et al. 2002, Shekhar et al. 2017).

\section{Past uses of estrogen-active compounds}

The developing organism is critically sensitive to both endogenous and exogenous hormones. The critical window of exposure depends on the time at which specific developmental events occur in particular tissues and organs. This effect has been well studied for exposure to diethylstilbestrol (DES). DES was synthesized as the first non-steroid estrogen, and was administered from the 1940s to 1970s to pregnant woman in order to prevent miscarriages by compensate the insufficient placental synthesis of estrogen. The number of pregnant woman treated with DES is unknown, but the estimated range is from 5-10 million (Giusti et al. 1995). However, DES was found to bind to ERs in the fetal reproductive tract, causing permanent alterations. This was one of the first findings demonstrating endocrine disruption, moreover in utero (Gore 2007). The use of DES was finally banned by the FDA in 1971 after the finding of an association between vaginal clear cell adenocarcinoma and in utero exposure to DES. Based on the ability to cause cancer in humans, the International Agency for Research for Cancer classified DES as a Group 1 human carcinogen. Similar effects were discovered in animals. Over time, various other reproductive abnormalities in daughters exposed to DES in utero were recognized, such as structural reproductive differences, complications in pregnancy and infertility. Evidence of irregular menstruation was found in the third generation of women exposed in utero to DES (TitusErnstoff et al. 2006). Reproductive tract abnormalities were also reported for sons exposed to DES, as well as the development of various types of cancer, but these effects were not as clearly associated (Giusti et al. 1995, Goldberg and Falcone 1999, Mitra and Philip 2014).

This case is now used a model for studying the mechanisms and toxicities of other estrogen mimic EDs, including their effects on epigenetics.

\section{Bisphenols}

Even before DES was used in clinical practice, the non-steroid estrogen bisphenol A (BPA) had been discovered. It was first synthesized in 1891, and in the 1930s was tested for use as a synthetic estrogen for clinical practice. However, DES was shown to have stronger estrogenic activity. Nevertheless, a different usage for BPA was found as the basis in the production of polycarbonate plastic materials and as an additive to other plastic materials (Rubin 2011). It is contained in various types of plastics, epoxide resins, dental fillings as well as in thermal receipts. BPA molecules are easily released from the structure of plastics at higher temperatures or in acid or alkaline conditions, resulting in exposure and effects to the human body (Brotons et al. 1995, Kang et al. 2003, Krishnan et al. 1993, Welshons et al. 2006). Besides estrogenic effects (Gould et al. 1998, Kuiper et al. 1998, Okada et al. 2008), BPA also interacts with the androgen receptor (Lee et al. 2003, Teng et al. 2013), thyroid receptor (Moriyama et al. 2002), glucocorticoid receptor (Sargis et al. 2010) and several others. BPA effects have been found at concentrations comparable to those of naturally-occurring hormones (Welshons et al. 2006).

In connection with the discovery of the negative effects of BPA, there has been ongoing debate concerning the safety of BPA. On the basis of two rodent multigenerational studies, the U.S. Food and Drug Administration (FDA) estimated a no observed adverse effect level (NOAEL) of $5 \mathrm{mg} / \mathrm{kg}$ body weight/day (Tyl et al. 2008, Tyl et al. 2002). In 2009, 2012 and 2014, FDA analyzed multiple studies relevant to the safety or risk assessment concerning BPA doses, but the results of those toxicity data and studies have not affected the existing dose-effect level and the existing NOAEL ( $5 \mathrm{mg} / \mathrm{kg}$ body weight/day; oral exposure). In 2012, FDA amended its regulations to no longer provide for the use of BPA-based polycarbonate resins in baby bottles and sippy cups in response to a food additive petition filed by the American Chemistry Council. One year later, in response to a petition filed by Congressman Edward Markley of Massachusetts, the FDA extended these restrictions for the use of BPA-based epoxy resins as coatings in packaging for infant formula (FDA 2014). The European Commission made the decision to restrict BPA in plastic baby bottles in the EU (Simoneau et al. 2011).

In connection with these restrictions, the usage of BPA was prohibited or regulated in several countries, especially in plastics for children and infants. Many "BPA-free plastics" were therefore introduced to the market; however, although the BPA-free label has proved 
to be a valuable marketing strategy, it provides no guarantee of a safer product. In these plastics, BPA was often replaced by analogues such as bisphenol S (BPS), bisphenol $\mathrm{F}$ (BPF), and bisphenol AF (BPAF). In principle, harmful compounds should ideally be substituted by inert or at least less-toxic substances than the original. Unfortunately, the majority of substitutes are not tested before their introduction to the market, and they often exhibit similar or even more potent disrupting effects than the originals. Such a replacement is called a "regrettable substitution" (Howard 2014). Results of various studies have indicated that the potencies, metabolism and mechanism of actions of BPS and BPF are similar to BPA, and considering hormonal actions they may pose similar potential health risks as BPA. For instance BPS has been found to be even more potent than BPA in in vivo mouse model of testosterone inhibition (Eladak et al. 2015, Rochester and Bolden 2015, Žalmanová et al. 2016). Despite these findings, monitoring and examining the effects of alternative bisphenols is still limited, and their use has not yet been regulated.

\section{BPA metabolism and exposure}

Although the main route of exposure to BPA is thought to be oral via the diet, dermal and inhalation exposure are also possible. The bonds between polycarbonate, epoxy-resins and BPA molecule are noncovalent (and therefore unstable), and physical and/or chemical factors, such as acidity or heat, can lead to leaching from BPA-containing materials (Giulivo et al. 2016). Concerning BPA metabolism, various studies have been published addressing this issue on animal models, and have been reviewed by Vandenberg et al. (2007). However, the major weakness of these studies is that humans experience multiple exposures each day. In addition, there is some evidence that BPA metabolism in rodents differs from the metabolic endpoints in primate models. In rodents, the majority of BPA is excreted in the feces, but in primates via the urine (Giulivo et al. 2016).

In humans, ingested BPA is believed to be rapidly absorbed from the gastrointestinal tract, then undergoes a first-pass effect in the metabolic tract and liver consisting of glucuronidation and to a lesser extent sulfatation, forming inactive BPA-monoglucuronide and BPA-sulfate at a level of approximately $98 \%$. In plasma, more than $90 \%$ of BPA is bound, depending on the route of exposure. Upon dermal exposure or exposure by inhalation, the first-pass liver effect is circumvented (Vandenberg et al. 2007) and unconjugated (active) BPA might circulate longer in the plasma. Conjugated BPA is excreted via the urine within 5-7 h after ingestion (Mattison et al. 2014). However, BPA is also known to have lipophilic properties and therefore has the potential to accumulate in fat stores. Also, a mild accumulation of BPA was found in seminal plasma in comparison with blood plasma (Vitku et al. 2015).

\section{The transplacental passage of BPA}

Many studies have examined the presence of BPA during pregnancy in various body fluids such as maternal urine, milk, amniotic fluid and placental fluid, as well as in neonates and young children (Braun et al. 2011, Cantonwine et al. 2015, Ferguson et al. 2015, Ikezuki et al. 2002, Vandenberg et al. 2007). BPA has been linked with reduced maturation of the oocytes, and adverse effects on the infant and young child including an increased risk of preterm delivery, preeclampsia, shortened gestation length and anthropometric measures at birth (Cantonwine et al. 2015, Giulivo et al. 2016, Leclerc et al. 2014, Pinney et al. 2017, Snijder et al. 2013). In addition, prenatal exposures to BPA have been linked to increased adiposity and abnormalities in glucose metabolism later in life (Vom Saal et al. 2012).

There is clear placental transport of BPA to the fetus. The major fraction of the compound transferred was found to be in an unconjugated form. Since BPA freely diffuses across the human placenta and only a negligible amount is conjugated by the placenta, the fetus is probably exposed to free BPA. The underdeveloped fetal liver cannot protect the fetus against constant exposure (Balakrishnan et al. 2010). It has been proposed that BPA may accumulate in early fetuses due to their lower metabolic clearance of BPA, and thus the human fetus may be exposed to levels that are even higher than those found in the mother's blood. BPA is therefore considered to bioaccumulate in the fetal compartment (Vandenberg et al. 2007). These findings highlight the necessity to avoid BPA contamination during pregnancy. However, the "BPA-free" plastics are not necessarily a safe substitution because of the presence of alternative bisphenols.

\section{Alternative bisphenols}

Recent studies of the leaching of bisphenols from 
beverage containers have detected similar amounts of BPA and PBF (Regueiro and Wenzl 2015). Total bisphenol levels are substantially higher than the levels of BPA alone. The rapid emergence BPA substitutes has not only complicated attempts to understand the risks posed by human BPA exposure, but also amplifies the problematics of risk assessment because the risk posed by each new bisphenol is now a concern (Sartain and Hunt 2016).

Studies investigating the metabolism and effects of prenatal exposure of alternative bisphenols have been very scarce. Only several studies have been published documenting the effects of BPS and BPF on laboratory or animal models. In 2015, Mersha et al. (2015) reported that in the laboratory model Caenorhabditis elegans, the exposure of embryos to BPA and BPS affects their behavior as adults in the same manner. In 2016, Chen et al. (2016) compared the effects of BPA and BPS on germline and reproductive functions using the same model system, and found that, similarly to BPA, BPS caused severe reproductive defects including germline apoptosis and embryonic lethality. Qiu et al. (2016) evaluated the impact of BPA and BPS on the reproductive neuroendocrine system during zebrafish embryonic and larval development, and found a similar effect for both bisphenols. These findings therefore raise new concerns about the safety of BPA alternatives and the risk associated with human exposure to mixtures of EDs.

In a rat study from 2006, BPF residues were detected in the uterus, placenta, amniotic fluid and fetuses, and the levels of BPF in the intrauterine compartment and maternal blood were comparable (Cabaton et al. 2006). Iwano et al. (2016) reported that $\mathrm{BPF}$ is metabolized to conjugated metabolites (BPF-glucuronide, BPF-sulfate and BPF-glucuronide/ sulfate) in the maternal liver of a tissue perfusion model. BPF sulfate was easy to pass to the embryo through the placenta. These results suggest that fetal risk of BPF toxicity might be even higher than BPA because of the drug-metabolizing system (metabolites with sulfate) during the perinatal period. Ohtani et al. (2017) reported that prenatal BPF exposure in mice altered the behavior of offspring, resulting in an increase of anxiety and depression. The behavioral adverse effects were in larger magnitude than BPA, suggesting the risk of using BPF as a substitute for BPA.

In the light of these concerns, the potential risk for the fetus from bisphenol exposure in pregnancy is likely an important issue. There are various restrictions and recommendations concerning BPA exposure to newborns and children; however, the risks associated with pregnancy are usually not highlighted. Considering the recent data it is also important to note that using "BPA-free" products is not a safe alternative for pregnant women.

\section{Parabens}

Further EDs of interest are the parabens. They are widely applied effective antimicrobial agents and preservatives used mainly in personal care products and pharmaceutic products, but also in several foodstuffs and industrial products. Chemically, they are esters of p-hydroxybenzoic acid with alkyl substituents ranging from methyl to butyl or benzyl groups. The most commonly used are methylparaben (MP) and propylparaben (PP), which are often present in the products together. Others commonly used are ethylparaben (EP), butylparaben (BP) and benzylparaben (BenzylP). The antimicrobial activity increases proportionally to the length of the alkyl substituent. Their bactericidal and fungicidal properties combined with low cost and low sensitizing has resulted in their widespread use in the various products mentioned above. After the discovery of their estrogenic potential, parabens were listed among EDs, and the European Union authorized their use in only limited amount (Bledzka et al. 2014). In addition to the estrogenic properties, some parabens have been reported to display anti-androgenic activity by binding to androgen receptors and causing the inhibition of testosterone-induced transcription. Their usage in cosmetic products is now limited in the EU, USA and Canada to $0.4 \%$ content for a single paraben and $0.8 \%$ for mixtures of all parabens (Buzek and Ask 2009). The Scientific Panel on Food Additives, Flavourings, Processing Aids and Materials in Contact with Food (AFC) at the European Food Safety Authority (EFSA) has established the Acceptable Daily Intake (ADI) of $0-10 \mathrm{mg} / \mathrm{kg} /$ day for MP and EP and their sodium salts in foods. However, the panel decided that PP would not be included in this group ADI, due to effects on several reproductive parameters in rats. While the presence of PP in the diet is limited and unlikely to represent a risk to consumers, the panel was unable to recommend a specific ADI for PP based on the current evidence (EFSA 2004, Soni et al. 2005).

On the current market, there are a still-increasing number of "paraben-free" products, especially in personal care products intended for children. However, in 
accordance with the relevant legislation, parabens are still extensively used and characterized as "safe". Taking into account the possibility of exposition to combinations of more than one ED and possible additions or multiplications of their effects, such "safe doses" may not be as safe as they appear.

\section{Paraben metabolism and exposure}

Parabens can enter the human body through ingestion, absorption through the skin and inhalation. The metabolism of parabens may differ between the exposure pathways. Transdermal absorption is related to the ability of parabens to cross the stratum corneum, which is determined by the length of the alkyl chain. In general, skin permeation decreases with increasing chain length (Andersen 2008, Vela-Soria et al. 2014). Parabens may accumulate in the body as a result of the daily application of several different paraben-containing products (Mathiesen et al. 2013). In some cases, such as the use of various cosmetic products against stretch marks, done especially in the late pregnancy, the area of skin where parabens may be applied is large. After uptake, parabens are metabolized by esterases, and are conjugated and excreted in the urine and bile. The main metabolite is p-hydroxybenzoic acid, a large proportion of which is excreted as its glycine conjugate - p-hydroxyhippuric acid. Following oral exposure, parabens are metabolized by esterases in the intestine and liver, and are excreted in the urine as well as in bile and feces (Boberg et al. 2010, Vela-Soria et al. 2014).

\section{The transplacental passage of parabens}

There have been various published studies discussing the possible effect of parabens on the fetus. The number of scientific reports documenting the endocrine disruption by parabens is still increasing, but most findings have been documented in animal models. It has been shown that exposure to environmental chemicals including parabens during the early development of the male reproductive system may be of crucial importance for male reproductive health later in life (Sharpe and Skakkebaek 2008). In utero exposure in females could lead to the early onset of puberty and the anti-androgenic effects of chemicals, while in the male fetus could contribute to a reduction in male reproductive capability (Jorgensen et al. 2012).

Fetal exposure to parabens with longer alkyl chains, such as PP, BP and BenzylP, is a matter of particular concern by Frederiksen et al. (2008). They demonstrated the accumulation of parabens (EP, BP) in the amniotic fluid of pregnant rats. After the subcutaneous administration of selected parabens, paraben levels in the amniotic fluid were higher than in the maternal plasma or in the fetal tissues. Philippat et al. (2013) examined paraben levels in the amniotic fluid of 69 women and detected PP and MP, while EP and BP were not detected. Vela-Soria et al. (2014) developed a method for the determination of selected parabens and benzophenones in human placental tissue. They measured these compounds in 10 placental tissue samples obtained from women at the moment of delivery, and detected MP and PP in the majority of the examined samples. In 2015, the first study reporting the transplacental passage of parabens was reported in humans (Towers et al. 2015). The authors analyzed 45 mother-child pairs (cord blood), and found both MP and BP in the maternal blood as well as in cord blood. However, the pharmacokinetics and metabolic characteristics of major parabens crossing the human placenta are largely unknown. Mathiesen et al. (2013) developed an in vitro human placental perfusion model in order to understand the basic mechanisms of the fetoplacental transport of parabens as well as facilitate risk assessments with the use of paraben-containing products during pregnancy. Valle-Sistac et al. (2016) examined selected parabens and benzophenones in 12 samples of placental tissue from healthy volunteer mothers. MP, BP and BenzylP were detected in all samples, and EP and PP were also frequently observed, with positive detections in nine and ten out of twelve placentas. In 2017, the group of Vela-Soria measured levels of selected parabens in 15 human placenta samples by a new LC-MS/MS method. PP was detected in all samples, but could not be quantified. MP and EP were detected in 13 and 10 samples and quantified in 5 and 6 samples, respectively. The most recent study (Shekhar et al. 2017) examined 40 pregnant women and reported paraben levels in the maternal blood plasma and amniotic fluid. The total unadjusted median concentrations were similar in both body fluids. The levels of MP and PP were on the order of $20 \mathrm{ng} / \mathrm{ml}$, and EP and BP were within 1-2 ng/ml (Shekhar et al. 2017). These findings show the potential of parabens to cross the placental barrier and thus possibly affect the fetus.

The findings of parabens in human placental tissue, cord blood and amniotic fluid highlight the need for further studies to fully understand the potential of mother-fetus transfer when using personal care products. 


\section{Endocrine disruptor interactions}

Humans are often exposed to many EDs at the same time, and an understanding of how individual EDs act or interact with others is essential, though very difficult to study. Among the EDs mentioned here, it will be of particular interest to determine the levels of alternative bisphenols in "BPA-free" products as well as in BPA-based materials, and assess the effects of exposure to multiple bisphenols together. Fernandez et al. (2016) published a statistically significant association between prenatal exposure to BPA and PP and the risk of male genital malformations. An even more recent study (Pollock et al. 2017) showed that BP and PP can alter the pharmacokinetics of BPA, and that BP can modulate estradiol concentrations in an in vivo animal model. Taking into account the widespread occurrence of a variety of parabens and studies reporting associations between parabens and bisphenols, exploring the effects of these substances on the human body could occupy an entire scientific career.

\section{Conclusion}

Due to increased environmental education, emerging scientific data, the development of analytical techniques and, above all, the increasing interest of people in their health, EDs have become an increasingly important topic. International authorities have established limits for the content of known EDs in food, beverages, and cosmetics Permitted limits are particularly restrictive with regard to the content of EDs in children's products. However, the most sensitive stages of human development take place in the developing fetus in the mother's body. As of yet, no specific measures have been put in place to regulate ED exposure to pregnant women. A large number of products intended for pregnant women contain parabens and bisphenols, which pass to the fetus and can affect its development. More attention should be paid to this underestimated fact, and the importance of avoiding products containing bisphenols and parabens during pregnancy should be highlighted.

\section{Conflict of Interest}

There is no conflict of interest.

\section{Acknowledgements}

This work was supported by the project $\mathrm{MH}$ CR 17-30528 A from the Czech Health Research Council, $\mathrm{MH} \mathrm{CZ} \mathrm{-} \mathrm{DRO} \mathrm{(Institute} \mathrm{of} \mathrm{Endocrinology} \mathrm{-} \mathrm{EÚ,}$ 00023761) and by the MEYS CR (OP RDE, Excellent research - ENDO.CZ).

\section{References}

ANDERSEN FA: Final amended report on the safety assessment of methylparaben, ethylparaben, propylparaben, isopropylparaben, butylparaben, isobutylparaben, and benzylparaben as used in cosmetic products. Int $J$ Toxicol 27: 1-82, 2008

BALAKRISHNAN B, HENARE K, THORSTENSEN EB, PONNAMPALAM AP, MITCHELL MD: Transfer of bisphenol A across the human placenta. Am J Obstet Gynecol 202: 393.e1-393.e7, 2010.

BARKER DJ: The developmental origins of adult disease. Eur J Epidemiol 18: 733-736, 2003.

BARRY JS, ANTHONY RV: The pregnant sheep as a model for human pregnancy. Theriogenology 69: 55-67, 2008.

BECK F: Comparative placental morphology and function. Environ Health Perspect 18: 5-12, 1976.

BERGMAN Å, HEINDEL JJ, JOBLING S, KIDD KA, ZOELLER RT, JOBLING SK: State of the science of endocrine disrupting chemicals 2012: an assessment of the state of the science of endocrine disruptors prepared by a group of experts for the United Nations Environment Programme and World Health Organization. World Health Organization, 2013.

BLEDZKA D, GROMADZINSKA J, WASOWICZ W: Parabens. From environmental studies to human health. Environ Int 67: 27-42, 2014.

BOBERG J, TAXVIG C, CHRISTIANSEN S, HASS U: Possible endocrine disrupting effects of parabens and their metabolites. Reprod Toxicol 30: 301-312, 2010.

BRAUN JM, KALKBRENNER AE, CALAFAT AM, YOLTON K, YE X, DIETRICH KN, LANPHEAR BP: Impact of early-life bisphenol A exposure on behavior and executive function in children. Pediatrics 128: 873-882, 2011. 
BROTONS JA, OLEA-SERRANO MF, VILLALOBOS M, PEDRAZA V, OLEA N: Xenoestrogens released from lacquer coatings in food cans. Environ Health Perspect 103: 608-612, 1995.

BUZEK J, ASK B: Regulation (EC) No 1223/2009 of the European Parliament and of the Council of 30 November 2009 on cosmetic products. OJ L 342, 2009.

CABATON N, CHAGNON MC, LHUGUENOT JC, CRAVEDI JP, ZALKO D: Disposition and metabolic profiling of bisphenol F in pregnant and nonpregnant rats. J Agr Food Chem 54: 10307-10314, 2006.

CANTONWINE DE, FERGUSON KK, MUKHERJEE B, MCELRATH TF, MEEKER JD: Urinary bisphenol A levels during pregnancy and risk of preterm birth. Environ Health Perspect 123: 895-901, 2015.

CHANG CH, CHEN ML, LIAO KW, TSAI YA, MAO IF, WANG TH, HWANG SM, CHANG YJ, TSAI MS: The association between maternal nonylphenol exposure and parity on neonatal birth weight: a cohort study in Taiwan. Chemosphere 93: 1145-1152, 2013.

CHEN Y, SHU L, QIU Z, LEE DY, SETTLE SJ, QUE HEE S, TELESCA D, YANG X, ALLARD P: Exposure to the BPA-substitute bisphenol S causes unique alterations of germline function. PLoS Genet 12: e1006223, 2016.

DARBRE PD: Entry into Human Tissues, Endocrine Disruption and Human Health. Academic Press, Cambridge, Massachusetts, 2015.

DIAMANTI-KANDARAKIS E, BOURGUIGNON JP, GIUDICE LC, HAUSER R, PRINS GS, SOTO AM, ZOELLER RT, GORE AC: Endocrine-disrupting chemicals: an Endocrine Society scientific statement. Endocr Rev 30: 293-342, 2009.

EFSA: Opinion of the Scientific Panel on Food Additives, Flavourings, Processing Aids and Materials in Contact with Food on a request from the Commission related to para hydroxybenzoates (E 214-219). EFSA J 83: 1-26, 2004.

ELADAK S, GRISIN T, MOISON D, GUERQUIN MJ, N'TUMBA-BYN T, POZZI-GAUDIN S, BENACHI A, LIVERA G, ROUILLER-FABRE V, HABERT R: A new chapter in the bisphenol A story: bisphenol S and bisphenol F are not safe alternatives to this compound. Fertil Steril 103: 11-21, 2015.

FDA: Bisphenol A (BPA): Use in food contact application. Update on Bisphenol A (BPA) for Use in Food Contact Applications. Available online at http://www.fda.gov/NewsEvents/PublicHealthFocus/ucm064437.htm, 2014.

FERGUSON KK, MCELRATH TF, CANTONWINE DE, MUKHERJEE B, MEEKER JD: Phthalate metabolites and bisphenol-A in association with circulating angiogenic biomarkers across pregnancy. Placenta 36: 699-703, 2015.

FERNANDEZ MF, ARREBOLA JP, JIMENEZ-DIAZ I, SAENZ JM, MOLINA-MOLINA JM, BALLESTEROS O, KORTENKAMP A, OLEA N: Bisphenol A and other phenols in human placenta from children with cryptorchidism or hypospadias. Reprod Toxicol 59: 89-95, 2016.

FREDERIKSEN H, TAXVIG C, HASS U, VINGGAARD AM, NELLEMANN C: Higher levels of ethyl paraben and butyl paraben in rat amniotic fluid than in maternal plasma after subcutaneous administration. Toxicol Sci 106: 376-383, 2008.

GIULIVO M, LOPEZ DE ALDA M, CAPRI E, BARCELO D: Human exposure to endocrine disrupting compounds: Their role in reproductive systems, metabolic syndrome and breast cancer. A review. Environ Res 151: 251-264, 2016.

GIUSTI RM, IWAMOTO K, HATCH EE: Diethylstilbestrol revisited: a review of the long-term health effects. Ann Intern Med 122: 778-788, 1995.

GOLDBERG JM, FALCONE T: Effect of diethylstilbestrol on reproductive function. Fertil Steril 72: 1-7, 1999.

GORE AC: Endocrine-Disrupting Chemicals: From Basic Research to Clinical Practice. Springer Science \& Business Media, Berlin, 2007.

GOULD JC, LEONARD LS, MANESS SC, WAGNER BL, CONNER K, ZACHAREWSKI T, SAFE S, MCDONNELL DP, GAIDO KW: Bisphenol A interacts with the estrogen receptor alpha in a distinct manner from estradiol. Mol Cell Endocrinol 142: 203-214, 1998.

HOWARD GJ: Chemical alternatives assessment: the case of flame retardants. Chemosphere 116: 112-117, 2014.

IKEZUKI Y, TSUTSUMI O, TAKAI Y, KAMEI Y, TAKETANI Y: Determination of bisphenol A concentrations in human biological fluids reveals significant early prenatal exposure. Hum Reprod 17: 2839-2841, 2002.

IWANO H, OHTANI N, HOZUMI N, INOUE H, YOKOTA H: Pharmacokinetic study of adverse effects in offspring caused by prenatal Bisphenol F exposure. Toxicol Lett 259 (Suppl): S113, 2016. 
JORGENSEN N, JOENSEN UN, JENSEN TK, JENSEN MB, ALMSTRUP K, OLESEN IA, JUUL A, ANDERSSON AM, CARLSEN E, PETERSEN JH, TOPPARI J, SKAKKEBAEK NE: Human semen quality in the new millennium: a prospective cross-sectional population-based study of 4867 men. BMJ Open 2: 1197, 2012.

KABIR ER, RAHMAN MS, RAHMAN I: A review on endocrine disruptors and their possible impacts on human health. Environ Toxicol Pharmacol 40: 241-258, 2015.

KANG JH, KITO K, KONDO F: Factors influencing the migration of bisphenol A from cans. $J$ Food Prot 66: 14441447, 2003.

KRISHNAN AV, STATHIS P, PERMUTH SF, TOKES L, FELDMAN D: Bisphenol-A: an estrogenic substance is released from polycarbonate flasks during autoclaving. Endocrinology 132: 2279-2286, 1993.

KUIPER GG, LEMMEN JG, CARLSSON B, CORTON JC, SAFE SH, VAN DER SAAG PT, VAN DER BURG B, GUSTAFSSON JA: Interaction of estrogenic chemicals and phytoestrogens with estrogen receptor beta. Endocrinology 139: 4252-4263, 1998.

LECLERC F, DUBOIS MF, ARIS A: Maternal, placental and fetal exposure to bisphenol A in women with and without preeclampsia. Hypertens Pregnancy 33: 341-348, 2014.

LEE HJ, CHATTOPADHYAY S, GONG EY, AHN RS, LEE K: Antiandrogenic effects of bisphenol A and nonylphenol on the function of androgen receptor. Toxicol Sci 75: 40-46, 2003.

MATHIESEN L, ZURI G, ANDERSEN MH, KNUDSEN LE: A proposed study on the transplacental transport of parabens in the human placental perfusion model. Altern Lab Anim 41: 473-482, 2013.

MATSUMOTO J, YOKOTA H, YUASA A: Developmental increases in rat hepatic microsomal UDPglucuronosyltransferase activities toward xenoestrogens and decreases during pregnancy. Environ Health Perspect 110: 193-196, 2002.

MATTISON DR, KARYAKINA N, GOODMAN M, LAKIND JS: Pharmaco- and toxicokinetics of selected exogenous and endogenous estrogens: a review of the data and identification of knowledge gaps. Crit Rev Toxicol 44: 696-724, 2014.

MERSHA MD, PATEL BM, PATEL D, RICHARDSON BN, DHILLON HS: Effects of BPA and BPS exposure limited to early embryogenesis persist to impair non-associative learning in adults. Behav Brain Funct 11: 27, 2015.

MITRA MS, PHILIP BK: Diethylstilbestrol A2. In: Encyclopedia of Toxicology (Third Edition). WEXLER P, Academic Press, Oxford, 2014, pp 143-145.

MODENA AB, FIENI S: Amniotic fluid dynamics. Acta Biomed 75 (Suppl 1): 11-13, 2004.

MORIYAMA K, TAGAMI T, AKAMIZU T, USUI T, SAIJO M, KANAMOTO N, HATAYA Y, SHIMATSU A, KUZUYA H, NAKAO K: Thyroid hormone action is disrupted by bisphenol A as an antagonist. $J$ Clin Endocrinol Metab 87: 5185-5190, 2002.

OHTANI N, IWANO H, SUDA K, TSUJI E, TANEMURA K, INOUE H, YOKOTA H: Adverse effects of maternal exposure to bisphenol F on the anxiety- and depression-like behavior of offspring. J Vet Med Sci 79: 432-439, 2017.

OKADA H, TOKUNAGA T, LIU X, TAKAYANAGI S, MATSUSHIMA A, SHIMOHIGASHI Y: Direct evidence revealing structural elements essential for the high binding ability of bisphenol A to human estrogen-related receptor-gamma. Environ Health Perspect 116: 32-38, 2008.

PHILIPPAT C, WOLFF MS, CALAFAT AM, YE X, BAUSELL R, MEADOWS M, STONE J, SLAMA R, ENGEL SM: Prenatal exposure to environmental phenols: concentrations in amniotic fluid and variability in urinary concentrations during pregnancy. Environ Health Perspect 121: 1225-1231, 2013.

PINNEY SE, MESAROS CA, SNYDER NW, BUSCH CM, XIAO R, AIJAZ S, IJAZ N, BLAIR IA, MANSON JM: Second trimester amniotic fluid bisphenol A concentration is associated with decreased birth weight in term infants. Reprod Toxicol 67: 1-9, 2017.

POLLOCK T, WEAVER RE, GHASEMI R, DECATANZARO D: Butyl paraben and propyl paraben modulate bisphenol A and estradiol concentrations in female and male mice. Toxicol Appl Pharmacol 325: 18-24, 2017.

QIU W, ZHAO Y, YANG M, FARAJZADEH M, PAN C, WAYNE NL: Actions of bisphenol A and bisphenol S on the reproductive neuroendocrine system during early development in zebrafish. Endocrinology 157: 636-647, 2016. 
REGUEIRO J, WENZL T: Determination of bisphenols in beverages by mixed-mode solid-phase extraction and liquid chromatography coupled to tandem mass spectrometry. J Chromatogr A 1422: 230-238, 2015.

ROCHESTER JR, BOLDEN AL: Bisphenol S and F: A systematic review and comparison of the hormonal activity of bisphenol A substitutes. Environ Health Perspect 123: 643-650, 2015.

RUBIN BS: Bisphenol A: an endocrine disruptor with widespread exposure and multiple effects. $J$ Steroid Biochem Mol Biol 127: 27-34, 2011.

SARGIS RM, JOHNSON DN, CHOUDHURY RA, BRADY MJ: Environmental endocrine disruptors promote adipogenesis in the 3T3-L1 cell line through glucocorticoid receptor activation. Obesity 18: 1283-1288, 2010.

SARTAIN CV, HUNT PA: An old culprit but a new story: bisphenol A and "NextGen" bisphenols. Fertil Steril 106: 820-826, 2016.

SCHUG TT, JANESICK A, BLUMBERG B, HEINDEL JJ: Endocrine disrupting chemicals and disease susceptibility. J Steroid Biochem Mol Biol 127: 204-215, 2011.

SHARPE RM, SKAKKEBAEK NE: Testicular dysgenesis syndrome: mechanistic insights and potential new downstream effects. Fertil Steril 89: e33-e38, 2008.

SHEKHAR S, SOOD S, SHOWKAT S, LITE C, CHANDRASEKHAR A, VAIRAMANI M, BARATHI S, SANTOSH W: Detection of phenolic endocrine disrupting chemicals (EDCs) from maternal blood plasma and amniotic fluid in Indian population. Gen Comp Endocrinol 241: 100-107, 2017.

SIMONEAU C, VALZACCHI S, MORKUNAS V, VAN DEN EEDE L: Comparison of migration from polyethersulphone and polycarbonate baby bottles. Food Addit Contam Part A Chem Anal Control Expo Risk Assess 28: 1763-1768, 2011.

SKAKKEBAEK NE, RAJPERT-DE MEYTS E, MAIN KM: Testicular dysgenesis syndrome: an increasingly common developmental disorder with environmental aspects. Hum Reprod 16: 972-978, 2001.

SNIJDER CA, HEEDERIK D, PIERIK FH, HOFMAN A, JADDOE VW, KOCH HM, LONGNECKER MP, BURDORF A: Fetal growth and prenatal exposure to bisphenol A: the generation R study. Environ Health Perspect 121: 393-398, 2013.

SONI MG, CARABIN IG, BURDOCK GA: Safety assessment of esters of p-hydroxybenzoic acid (parabens). Food Chem Toxicol 43: 985-1015, 2005.

SUGIURA-OGASAWARA M, OZAKI Y, SONTA S, MAKINO T, SUZUMORI K: Exposure to bisphenol A is associated with recurrent miscarriage. Hum Reprod 20: 2325-2329, 2005.

TENG C, GOODWIN B, SHOCKLEY K, XIA M, HUANG R, NORRIS J, MERRICK BA, JETTEN AM, AUSTIN CP, TICE RR: Bisphenol A affects androgen receptor function via multiple mechanisms. Chem Biol Interact 203: 556-564, 2013.

TITUS-ERNSTOFF L, TROISI R, HATCH EE, WISE LA, PALMER J, HYER M, KAUFMAN R, ADAM E, STROHSNITTER W, NOLLER K, HERBST AL, GIBSON-CHAMBERS J, HARTGE P, HOOVER RN: Menstrual and reproductive characteristics of women whose mothers were exposed in utero to diethylstilbestrol (DES). Int J Epidemiol 35: 862-868, 2006.

TOWERS CV, TERRY PD, LEWIS D, HOWARD B, CHAMBERS W, ARMISTEAD C, WEITZ B, PORTER S, BORMAN CJ, KENNEDY RC, CHEN J: Transplacental passage of antimicrobial paraben preservatives. J Expo Sci Environ Epidemiol 25: 604-607, 2015.

TYL RW, MYERS CB, MARR MC, THOMAS BF, KEIMOWITZ AR, BRINE DR, VESELICA MM, FAIL PA, CHANG TY, SEELY JC, JOINER RL, BUTALA JH, DIMOND SS, CAGEN SZ, SHIOTSUKA RN, STROPP GD, WAECHTER JM: Three-generation reproductive toxicity study of dietary bisphenol A in CD Sprague-Dawley rats. Toxicol Sci 68: 121-146, 2002.

TYL RW, MYERS CB, MARR MC, SLOAN CS, CASTILLO NP, VESELICA MM, SEELY JC, DIMOND SS, VAN MILLER JP, SHIOTSUKA RN, BEYER D, HENTGES SG, WAECHTER JM JR: Two-generation reproductive toxicity study of dietary bisphenol A in CD-1 (Swiss) mice. Toxicol Sci 104: 362-384, 2008.

VALLE-SISTAC J, MOLINS-DELGADO D, DIAZ M, IBANEZ L, BARCELO D, SILVIA DIAZ-CRUZ M: Determination of parabens and benzophenone-type UV filters in human placenta. First description of the existence of benzyl paraben and benzophenone-4. Environ Int 88: 243-249, 2016. 
VANDENBERG LN, HAUSER R, MARCUS M, OLEA N, WELSHONS WV: Human exposure to bisphenol A (BPA). Reprod Toxicol 24: 139-177, 2007.

VELA-SORIA F, RODRIGUEZ I, BALLESTEROS O, ZAFRA-GOMEZ A, BALLESTEROS L, CELA R, NAVALON A: Simplified matrix solid phase dispersion procedure for the determination of parabens and benzophenone-ultraviolet filters in human placental tissue samples. J Chromatogr A 1371: 39-47, 2014.

VITKU J, SOSVOROVA L, CHLUPACOVA T, HAMPL R, HILL M, SOBOTKA V, HERACEK J, BICIKOVA M, STARKA L: Differences in bisphenol A and estrogen levels in the plasma and seminal plasma of men with different degrees of infertility. Physiol Res 64 (Suppl 2): S303-S311, 2015.

VOM SAAL FS, NAGEL SC, COE BL, ANGLE BM, TAYLOR JA: The estrogenic endocrine disrupting chemical bisphenol A (BPA) and obesity. Mol Cell Endocrinol 354: 74-84, 2012.

WELSHONS WV, NAGEL SC, VOM SAAL FS: Large effects from small exposures. III. Endocrine mechanisms mediating effects of bisphenol A at levels of human exposure. Endocrinology 147: S56-S69, 2006.

ŽALMANOVÁ T, HOŠKOVÁ K, NEVORAL J, PROKEŠOVÁ Š, ZÁMOSTNÁ K, KOTT T, PETR J: Bisphenol S instead of bisphenol A: a story of reproductive disruption by regretable substitution - a review. Czech J Anim Sci 61: 433-449, 2016. 